\title{
Understanding the basics of cannabidiol from cannabis to apply to therapeutics in epilepsy
}

\author{
L Hay, PhD \\ Department of Physiology, Sefako Makgatho Health Sciences University. Pretoria, South Africa
}

The compounds present in cannabis have been in use for both recreational and medicinal purposes for many centuries. Changes in the legislation in South Africa have led to an increase in the number of people interested in using these compounds for self-medication. Many of them may approach their general practitioner as the first source of information about possible therapeutic effects. It is important that medical professionals are able to give patients the correct information. Cannabidiol (CBD) is one of the main compounds in cannabis plants, and there is evidence that it can successfully treat certain patients with epilepsy. This review looks at the most recent evidence on the use of $\mathrm{CBD}$ in the treatment of epilepsy and explores the mechanisms behind these beneficial effects.

S Afr Med J 2020;110(2):102-105. https://doi.org/10.7196/SAMJ.2020.v110i2.14410

Marijuana or the products from the plant Cannabis sativa have been used both as a recreational drug and for the treatment of various diseases for thousands of years. ${ }^{[1]}$ In South Africa (SA) the local Khoisan used it before the arrival of European settlers. ${ }^{[2]}$ This use continued until the law criminalised it in 1922. Recently the Constitutional Court overturned the law by declaring the products of cannabis legal for private use. ${ }^{[3]}$ In spite of previous legislation, the South African Medical Research Council estimated that in the year 2008 there were $\sim 3.2$ million users of marijuana in SA. ${ }^{[4]}$ At that stage the country was regarded as the fourth-biggest producer of marijuana in the world. ${ }^{[4]}$

Not all users of cannabis products use them for recreational purposes - many are in fact self-medicating. The recent changes in legislation in SA have probably led to an increase in self-medication, but very little official information is available on the magnitude of this increase. Media interest indicates that it could be significant. Medical professionals are often not told that their patients are using these products, and they are not always aware of their possible benefits or adverse effects. Some patients may approach their doctor for assistance and information. Cannabis compounds are used for a variety of conditions, including pain, cancer, insomnia, inflammatory disease and epilepsy. ${ }^{[5]}$ Although scientists have investigated the therapeutic value of cannabis in many of these conditions, the results are often inconclusive and more work is needed. In some conditions, such as epilepsy, there is evidence that patients can benefit from using cannabidiol (CBD) extracted from cannabis, and this information could assist general practitioners in advising patients on the efficacy of these compounds.

\section{Objectives}

The objective of this review is to summarise the currently available information on the therapeutic effects of CBD, one of the main components of cannabis, in the treatment of epilepsy and to explore recent information on the mechanisms involved in these effects.

\section{Methods}

Several searches were done on PubMed (https://www.ncbi.nlm.nih. gov/pubmed/) during the period June/July 2019. The key words 'epilepsy', 'clinical studies,' 'therapeutic use', 'adverse effects' and 'drug interactions' were used in combination with 'cannabis', 'cannabinoids' and 'cannabidiol'. The abstracts were studied and the full text of articles of interest was acquired. Information from articles where it was not possible to get the full text was not included in the review.

\section{Literature review}

The family Cannabaceae consists of three species, namely C. sativa, C. indica and C. ruderalis. ${ }^{[5,6]}$ Owing to hybridisation, it is often difficult to distinguish between the different species. C. sativa is mostly known for its recreational use, whereas $C$. indica, commonly known as hemp, has been cultivated over the years for its fibres, which are used in the manufacturing of fabrics. ${ }^{[5-7]}$ This plant family contains more than 460 different chemicals, of which over 100 are classified as cannabinoids. ${ }^{[1]}$ The chemical composition of the different species is different, especially with regard to the two major components, tetrahydrocannabinol (THC) and CBD. Their proportions differ in the different species, with THC being higher in C. sativa and CBD higher in C. indica. ${ }^{[5]}$ One source quotes the ratio of $\mathrm{CBD} / \mathrm{THC}$ in C. indica as 30:1. ${ }^{[8]}$ These proportions may vary depending on many external factors the plants are exposed to, such as temperature, climate, time of harvesting and storage. ${ }^{[6]}$

Owing to past use and a continuous stream of anecdotal reports suggesting possible therapeutic advantages that can be obtained from using the cannabinoids, combined with the fact that more countries are moving towards lifting legislation prohibiting use, scientific interest in these compounds has shown a dramatic increase in the past decade. ${ }^{[6]}$

\section{The endocannabinoid system}

The search for receptors for the cannabinoids led to the discovery not only of the receptors but also of the endocannabinoid system (ECS) and the compounds $\mathrm{N}$-arachidonoylethanolamide, also known as anandamide, $\mathrm{N}$-oleoylethanolamide, $\mathrm{N}$-palmatoylethanolamide, $\mathrm{N}$-arachidonoyldopamine and 2-arachidonoyl glycerol (2-AG), which act as the chemical messengers of the ECS. ${ }^{[9,10]}$ Of these compounds, anandamide and 2-AG have been extensively studied and are regarded by some as the physiologically most important of the endocannabinoids. ${ }^{[5,6,10]}$ Although a lot of work still needs to be done on the ECS, it is speculated that it regulates various physiological processes including mood, pain perception, appetite and some cognitive functions. ${ }^{[1]}$ It is also proposed that this system 
is activated by the same factors that cause release of the endogenous opioids, such as stress and exercise. ${ }^{[12]}$ The suggestion is that these different endogenous systems co-ordinate to form a modulating system that mediates the responses of the body's control systems to different types of stress. ${ }^{[12]}$

The main targets of the endocannabinoids seem to be the G-protein-coupled $\mathrm{CB}_{1}$ and $\mathrm{CB}_{2}$ receptors, although there is evidence that many other receptors are involved in the actions of these compounds. ${ }^{[6]}$ The receptors are found in the central nervous system and on some peripheral nerves and also outside the nervous system on many different blood cells such as the B cells, natural killer cells, monocytes and neutrophils, as well as CD4 and CD8 T cells. ${ }^{[7]}$ The expression of the $\mathrm{CB}_{1}$ and $\mathrm{CB}_{2}$ receptors in the central nervous system is very different. ${ }^{[13]} \mathrm{CB}_{1}$ receptors are found in high numbers in the neocortex, basal nuclei, hippocampus and amygdala in the brain, as well as on interneurons in the dorsal horn of the spinal cord. ${ }^{[7]}$ The $\mathrm{CB}_{2}$ receptors in the central nervous system are mainly found on the microglia, although there is evidence of $\mathrm{CB}_{2}$ receptors in primary afferents involved in pain pathways. ${ }^{[14]}$ Although $\mathrm{CB}_{1}$ receptors are found on the immune cells, their numbers on the $\mathrm{T}$ cells are lower than those of the other immune cells mentioned above. $\mathrm{CB}_{2}$ receptors are also well expressed on the same blood cells as the $\mathrm{CB}_{1}$ receptors, again with lower numbers on the $\mathrm{T}$ cells. ${ }^{[7]}$ The physiological role of the endocannabinoids in the activities of the blood cells involves the modulation of inflammation. ${ }^{[7]}$ Activation of the $\mathrm{CB}_{2}$ receptors inhibits the production of the cytokines tumour necrosis factor (TNF)-alpha, interleukin (IL)-6 and IL-8 by monocytes and macrophages and TNF-alpha, IL- 2 and interferon (IFN)- $\gamma$ by $\mathrm{T}$ cells. ${ }^{[7]}$ All these are pro-inflammatory cytokines. ${ }^{[7]}$ There is, however, evidence that both types of receptors are present on other tissues in the body such as muscle, skin, bone and liver. ${ }^{[9,10]}$

\section{Phytocannabinoids}

The two main components of cannabis are THC and CBD, but although cannabidavarin (CBDV) and cannabinol (CBN) are present in lower concentrations, they are known to have neuroactive properties. ${ }^{[5,6,15]}$ THC is well known for its psychoactive properties, which are also associated with adverse effects such as dizziness, nausea, drowsiness, mood disorders and psychosis. ${ }^{[5]}$ Because of these adverse effects, THC is the least favoured compound of cannabis for possible therapeutic use. ${ }^{[5,6,12]}$ For unknown reasons, CBDV and CBN have also not received a lot of attention from researchers, and little literature on the effects of these two compounds is available. ${ }^{[15]}$ $\mathrm{CBD}$, on the other hand, is well tolerated even at relatively high doses (studies have reported doses of $10-600 \mathrm{mg} / \mathrm{d}$ ) ${ }^{[, 11,1,16,17]}$ and has therefore received much attention. Although it has been well tolerated by most participants, adverse effects such as loss of appetite, somnolence, some gastrointestinal disturbances and nausea have been reported in some studies, often to the extent that participants had to withdraw. ${ }^{[6,8,17]}$ Although CBD has few or no adverse effects in the majority of patients, it is important to note that no information is available on its possible long-term effects on the nervous system, especially on the developing brain. ${ }^{[6,18]}$ The shorter- to medium-term effects of $\mathrm{CBD}$ on various aspects of the normal physiology have been studied extensively in the past few years, as well as its potential therapeutic use in a variety of conditions. ${ }^{[5,6,19]}$ Therapeutic use has included its antiemetic and appetite-stimulatory effects and a possible role in the treatment of anxiety, depression, some types of cancer, Parkinson's disease, Alzheimer's disease, multiple sclerosis, glaucoma, chronic and neuropathic pain, inflammation and epilepsy. ${ }^{[5,6,7,19-21]}$ It is clear from the literature that the actions of the cannabinoids are complex and involve not only neuronal targets but also targets outside the nervous system. ${ }^{[13]}$ The presence of receptors on blood cells and their role in the manipulation of the inflammatory response has the potential for interesting therapeutic interventions, but lies outside the scope of this review.

Cannabinoids can be administered topically, orally, sublingually or by inhalation; of these, smoking is the best known. ${ }^{[9,19]}$ THC mainly targets the $\mathrm{CB}_{1}$ and $\mathrm{CB}_{2}$ receptors but has been found also to be an agonist for various receptors such as transient receptor potential ankyrin type 1 (TRPA1), transient potential vanilloid receptor types 1 (TRPV1) and 2 (TRPV2), G-protein-coupled receptor 18 (GPR18) and GPR55. ${ }^{[6,13,20]}$ CBD, on the other hand, does not have a high affinity for the $\mathrm{CB}_{1} / \mathrm{CB}_{2}$ receptors, but in high concentrations acts as an antagonist for $\mathrm{CB}_{1}$ and as an inverse agonist for $\mathrm{CB}_{2}{ }^{[6]} \mathrm{In}$ animal models, CBD has been confirmed as an agonist for many other receptors such as TRPV1-4, TRPA, alpha- 1 and alpha-3 glycine receptors and 5-hydroxytryptamine subtype 1a receptors, and as an antagonist for transient receptor melastatin type $8 .^{[9,13,17]}$ One of the more prominent ones seems to be the GPR55 receptor, which has been suggested to be a cannabinoid receptor, but this point is still controversial. ${ }^{[9,20,22]}$ In a study on Parkinson's disease, CBD was found to be an inverse agonist for GPR3, GPR6 and GPR12 and was of therapeutic significance in this condition. ${ }^{[20]}$ It is also known to modulate adenosine $\mathrm{A} 1$ and $\mathrm{A} 2$ receptors. ${ }^{[23,24]}$

The therapeutic possibilities of the phytocannabinoids have been investigated in both animal and clinical studies, leading to the development of various synthetic cannabinoids of which some have been registered as medications (such as dronabinol, levonantradol and nabilone, which are derivatives of THC). ${ }^{[13,21]}$ Others, such as nabiximols and Sativex, contain both THC and CBD, whereas Epidiolex contains only synthetic CBD. ${ }^{[13,19,21]}$ None of these drugs are registered in SA. Interestingly, studies have shown that the herbal cannabinoids were four times more potent than the synthetically prepared products or purified $\mathrm{CBD},{ }^{[8]}$ which seems to suggest a synergistic contribution from other compounds in the herbal preparations. ${ }^{[8]}$

Although encouraging results have been found in the therapeutic use of cannabinoids for various conditions in animal studies, there were initially few clinical studies that reproduced these benefits. In the earlier studies, results were compromised by small patient numbers and complicating factors such as experimental designs that left them open to criticism. ${ }^{[9,19,25,26]}$ Epilepsy was chosen as the focus of the present review because there appear to be more reproducible studies in terms of therapeutic CBD benefits in this condition than in others. I therefore looked at the available data from studies investigating the therapeutic potential of $\mathrm{CBD}$ in the treatment of epilepsy and explored the mechanisms behind these possible benefits.

\section{Epilepsy}

Approximately $1 \%$ of the world's population suffers from epilepsy, and it is estimated that $20-30 \%$ of sufferers do not achieve seizure control with conventional pharmacotherapies. ${ }^{[27-29]}$ Various anecdotal reports have indicated that some of these individuals have benefited from using CBD. These reports ranged from cases in which seizures were reduced to others that reported complete cessation of seizures, ${ }^{[8,13,18]}$ and they have elicited and increased scientific exploration of the possible therapeutic properties of $\mathrm{CBD}$ in recent years. ${ }^{[8]}$

Initial research focused on animal models of epilepsy, and CBD was shown to have anticonvulsant properties in several of these models. ${ }^{[18,25]}$ In some reports, the beneficial effects of CBD were enhanced by co-administration of conventional antiepileptic 
drugs. ${ }^{[18,25]}$ Animal studies were followed by several clinical studies, and the role of co-administration of conventional drugs with $\mathrm{CBD}$ became very relevant in the evaluation of the results because for ethical reasons the study participants could not be required to discontinue their conventional therapies while receiving $\mathrm{CBD} \cdot{ }^{[15]}$ For this reason, clinical studies on patients receiving only CBD are limited.

The results from the first clinical studies were therefore treated with caution, as sceptics were quick to point out the possible contribution of the drugs co-administered with the CBD. ${ }^{[13]}$ The fact that often the results were not from randomised, double-blind, placebo-controlled trials also left a question mark over the benefits of CBD ${ }^{[6,18]}$ However, in spite of criticism these early studies already suggested that CBD treatment was advantageous to patients who did not respond to conventional anticonvulsive therapy. Devinsky et al. ${ }^{[30]}$ showed a $30 \%$ reduction in motor seizures in 12 weeks of treatment in such patients. Subsequent studies comprising cohorts of different age groups ranging from infants to adults also supported the anticonvulsant properties of CBD. ${ }^{[8]}$

Although some of these studies had relatively big sample sizes and the results were supported by statistics, reviewers were still critical of their validity because of experimental designs that were deemed to detract from the value of the observations. These concerns were, however, subsequently addressed when the benefits of CBD were confirmed by well-controlled randomised trials for both LennoxGastaut and Dravet syndromes. ${ }^{[31-34]}$ These beneficial effects of CBD were further confirmed by many other clinical studies that followed, and also by meta-analytical reviews of the published data on different types of epilepsy in patients of various ages ranging from babies to adults..$^{[8,17,31-34]}$ Benefits included a $>50 \%$ (in some reports $80 \%$ ) decrease in the seizure rate, and some patients experienced a complete cessation of seizures. ${ }^{[17]}$ However, it is necessary to mention that in many of these studies some participants withdrew because of adverse effects, once again highlighting the important role of the genetic make-up of individuals in determining how they respond to these compounds. ${ }^{[6,17]}$

Genetic variability was one of the complicating factors in interpreting the data from the earlier studies. Various studies have reported large inter-individual variability in reaction to the action of CBD. ${ }^{[6,15,35]}$ This variability was highlighted in a study of CBD on pain perception in which some participants reported significant analgesia, others were not affected at all, and others reported experiencing hyperalgesia. ${ }^{[10]}$ Another factor that complicated interpretation of the results was the contribution of the placebo effect. Because of the interest around cannabis, it was found that participants had extremely high expectations, and Pamplona et al..$^{[8]}$ refer to studies that recorded placebo effects as high as $40 \%$, although they also state that in epilepsy studies a placebo effect of $15-25 \%$ is common. Such high percentages for placebo have a major effect on statistical analysis and the significance of recorded observations for the experimental groups. In spite of these factors, evidence that the majority of subjects in clinical trials benefit from the treatment of epilepsy with CBD is overwhelming.

\section{Mechanism of action}

In view of the above, it is important to investigate the mechanisms responsible for the anticonvulsant therapeutic benefits of CBD. A great deal of information on the mechanism of the anticonvulsive actions of $\mathrm{CBD}$ has become available in recent years. These mechanisms can be divided into those that involve manipulation of the ECS and those that are more direct. The ECS plays an important role in the control of synaptic transmission and through this regulates the excitability of neuronal networks in the nervous system. ${ }^{[12]}$
$\mathrm{CB}$ receptors are expressed presynaptically on glutamatergic and GABAergic interneurons and can thereby modulate the release of their neurotransmitters. ${ }^{[6]}$ The ECS is generally regarded as being anticonvulsive by preventing hyperexcitability, and deficiencies in this system have been linked to the pathophysiology of certain types of epilepsy. ${ }^{[2,36-39]}$

Although we know that $\mathrm{CBD}$ has a low affinity for the $\mathrm{CB}_{1} /$ $\mathrm{CB}_{2}$ receptors, it can therefore indirectly modulate these receptors by enhancing the actions of the ECS. ${ }^{[13]}$ It does so via various mechanisms, the first of which is to prolong the effect of anandamide by inhibition of its reuptake. ${ }^{[10,20]}$ Secondly, it inhibits amide hydrolase, 5-lipoxygenase and fatty acid amide hydrolyze, the enzymes responsible for the degradation of the endocannabinoids. ${ }^{[7,10,13,20]}$

Most conventional antiepileptic drugs act to reduce neuronal excitability by either blocking the release of excitatory neurotransmitters such as glutamate or by enhancing the release of inhibitory neurotransmitters such as GABA. ${ }^{[17]}$ The evidence is that antiepileptic drugs also target voltage-gated ion channels. ${ }^{[17]}$ This mechanism involves the targeting of specific ion channels, namely the $\mathrm{Na}^{+}$and $\mathrm{Ca}^{2+}$ channels, where some drugs would target either one of the two and others actually target both. ${ }^{[22]}$ Indications are that the more direct effects of the endocannabinoids may also employ these mechanisms. Although CBD has a low affinity for the CBD receptors, it has a high affinity for binding to the TRPV receptors, among others. ${ }^{[17]}$ Activation of the TRPV receptors normally increases the $\mathrm{Ca}^{2+}$ permeability of neuronal membranes, resulting in the increased release of glutamate. Through the interaction of CBD with the TRPV receptors, these receptors are desensitised and the intracellular $\mathrm{Ca}^{2+}$ is normalised, thereby preventing the release of glutamate. ${ }^{[17]}$ The inhibition of glutamate release is a well-known occurrence that results from $\mathrm{CB}_{1}$ receptor stimulation, but since $\mathrm{CBD}$ does not stimulate these receptors directly, the effect would be an indirect one by enhancing the ECS, as CBD downregulates fatty acid amide hydrolase and 5-lipoxygenase enzymes to increase anandamide levels. ${ }^{[20,40]} \mathrm{CBD}$ has also been shown to block T-type $\mathrm{Ca}^{2+}$ channels that normally increase the excitability of neurons. ${ }^{[17]}$ Abnormalities in the activation of these channels have also been implicated as involved in some types of epilepsy. ${ }^{[41]}$

Other channels that have been implicated as involved in epilepsy are the 5-hydroxytryptamine (HT) receptors. ${ }^{[6,13,17,20]}$ They form part of a group of G-protein-coupled receptors that can be subdivided into seven different classes $\left(5-\mathrm{HT}_{1-7}\right) .{ }^{[17]}$ These are serotonin receptors, and although they are thought to be involved in the aetiology of epilepsy, the exact mechanisms are not currently clear. ${ }^{[6,711,17]}$ It is, however, known that CBD has a high affinity for the two subtypes $5-\mathrm{HT}_{1 \mathrm{~A}}$ and $5-\mathrm{HT}_{2 \mathrm{~A}}$, and the suggestion is that some of the anticonvulsive effects of CBD can be attributed to its action via these receptors. ${ }^{[17]}$ Similarly, the opioid receptors (ORs) have been implicated in the aetiology of epilepsy, and they have also been linked to CBD. ${ }^{[14,17,21]}$ The ORs are incidentally also G-protein-coupled receptors, and the anticonvulsive effects of $\mathrm{CBD}$ are linked to the fact that they block the mu- and delta-ORs. ${ }^{[17]}$ Although it is outside the scope of this review, I would like to note that these receptors also make for some exciting prospects in the therapeutic use of CBD for the treatment of pain in conjunction with current opioid therapies. ${ }^{[14]}$

The exact physiological roles of another G-protein-coupled receptor, GPR55, are still controversial, but there is evidence that CBD acts as an antagonist for these receptors and it is suggested that this antagonism also contributes to the anticonvulsive effects of CBD. ${ }^{[6,7,20]}$ Normally GPR55 stimulation leads to intracellular $\mathrm{Ca}^{2+}$ mobilisation and a subsequent glutamate release that is abolished by the $\mathrm{CBD}$ binding to these receptors. ${ }^{[2]}$ 
The last mechanism to consider is one involving adenosine. Evidence in the literature points to the fact that $\mathrm{CBD}$ inhibits the reuptake of adenosine. ${ }^{[6,7,72-44]}$ Adenosine normally acts as a neuroprotective agent in the central nervous system, and its levels usually increase under conditions of stress. Earlier I alluded to the fact that the ECS plays a role in modulating the nervous system responses to stress. The fact that $\mathrm{CBD}$ administration assists in increasing adenosine levels in the nervous system would support such a mechanism. Adenosine action via the adenosine A1 receptors opens $\mathrm{K}^{+}$channels to hyperpolarise neurons and thereby reduce their excitability, which would be an obvious advantage in epilepsy. ${ }^{[43]}$ Via the same receptor, adenosine can also inhibit the N-type voltagegated $\mathrm{Ca}^{2+}$ channel to inhibit the release of glutamate, which normally increases the excitability of neuronal networks. ${ }^{[4]}$

\section{Conclusions}

The therapeutic benefit of $\mathrm{CBD}$ administration in the treatment of epilepsy has been established without doubt in other countries. It is, however, important to understand that owing to genetic variability there are some patients who do not receive benefit from this treatment. This is particularly important in SA, which has a population that represents a large genetic diversity. There is therefore a great need for clinical trials in SA involving patients who represent the diversity of the country and are not responding well to currently available drugs in order to establish how these patients could best benefit from this new therapeutic approach. It is also important to note that herbal preparations from cannabis plants can be of inconsistent quality, mainly because these plants are cultivated under a variety of conditions. As cannabis products are currently very topical and are becoming more readily available in SA, medical professionals need to increase their knowledge about the possible therapeutic benefits and adverse effects of the various compounds obtained from these plants.

\section{Declaration. None.}

Acknowledgements. None.

Author contributions. Sole author.

Funding. None.

Conflicts of interest. None.

1. McKim WA. Drugs and Behaviour: An Introduction to Behavioural Pharmacology. 4th ed. Uppe Saddle River, NJ: Prentice-Hall, 2000:400

2. Eyewitness News. ConCourt upholds ruling that private use of dagga is legal. https://ewn. co.za/2018/09/18/concourt-upholds-ruling-that-private-use-of-dagga-is-legal (accessed 20 June 2019).

3. Chanock M. The Making of South African Legal Culture 1902 - 1936: Fear, Favour and Prejudice. Melbourne, Australia: Cambridge University Press, 2001:92-94. https://doi.org/10.1017/ CBO9780511495403

4. Department of Social Development, South Africa. Snap-shot survey report on substance abuse in the nine provinces of South Africa. https://www.hst.org.za/publications/NonHST\%20 Publications/175300445-Snap-shot-survey-report-on-substance-abuse-in-the-nine-provinces-inSouth-Africa.pdf (accessed 20 June 2019).

5. Amar BA. Cannabinoids in medicine: A review of their therapeutic potential. J Ethnopharmacol 2006;105(1-2):1-25. https://doi.org/10.1016/j.jep.2006.02.001

6. Perucca E. Cannabinoids in the treatment of epilepsy: Hard evidence at last? Epilepsy Res 2017;7(2):6176. https://doi.org/ $10.14581 /$ jer. 17012

7. Pellati F, Borgonetti V, Brighenti V, Biagi M, Benvenuti S, Corsi L. Cannabis sativa L. and nonpsychoactive cannnabinoids: Their chemistry and role against oxidative stress, inflammation, and nonpsychoactive cannnabinoids: Their chemistry and role against oxidative stress
cancer. Biomed Res Int 2018;4;1691428. https://doi.org/10.1155/2018/1691428

8. Pamplona FA, da Silva L, Coan AC. Potential clinical benefits of CBD-rich cannabis extracts Pamplona FA, da Silva $\mathrm{L}$, Coan $\mathrm{AC}$. Potential clinical benefits of CBD-rich cannabis extracts
over purified $\mathrm{CBD}$ in treatment resistant epilepsy: Observational data meta-analysis. Front over purified CBD in treatment resistant epilepsy: Observational data meta-analysis. Front
Neurol 2018;9:759. https://doi.org/10.3389/fneur.2018.00759 (erratum https://doi.org/10.3389/

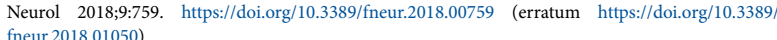
fneur.2018.01050)

9. Devinsky O, Cilio MR, Fernandez-Ruiz J, et al. Cannabidiol: Pharmacology and potential therapeutic role in epilepsy and other neuropsychiatric disorders. Epilepsia 2014;55(6):791-802. https://doi org/10.1111/epi.12631
10. Lotsch J, Weyer-Menkhoff I, Tegede I. Current evidence of cannabinoid-based analgesia obtained in preclinical and human experimental settings. Eur J Pain 2018;22(3):1-33. https://doi.org/10.1002/ ejp.1148

11. Shannon S, Lewis N, Lee H, Hughes S. Cannabidiol in anxiety and sleep: A large case series. Perm J 2019;23:18-041. https://doi.org/10.7812/TPP/18-041

12. Crombie KM, Leitzelar BN, Brellenthin AG, et al. Loss of exercise- and stress-induced increases in circulating 2-arachidonoylglycerol concentrations in adults with chronic PTSD. Biol Psychol 2019;145:1- 7. https://doi.org/10.1016/j.biopsycho.2019.04.002

13. Reddy DS, Golub VM. The pharmacological basis of cannabis therapy for epilepsy. J Pharmacol Exp Ther 2016;357(1):45-55. https://doi.org/10.1124/jpet.115.230151

14. Nielsen S, Sabioni P, Trigo JM, et al. Opioid-sparing effect of cannabinoids: A systematic review and meta-analysis. Neuropsychopharmacology 2017;42(9):1752-1765. https://doi.org/10.1038/ npp. 2017.51

15. Brodie MJ, Ben-Menachem E. Cannabinoids for epilepsy: What do we know and where do we go? Epilepsia 2019;59(2):291-296. https://doi.org/10.1111/epi.13973

16. Shirazi-Zand Z, Ahmad-Molaei L, Motamedi F, et al. The role of potassium BK channels in anticonvulsant effect of cannabidiol in pentylenetetrazole and maximal electroshock models of seizures in mice. Epilepsy Behav 2013:28(1):1-7. https://doi.org/10.1016/.j.yebeh.2013.03.009

17. Silvestro S, Mammana S, Cavalli E, et al. Use of cannabidiol in the treatment of epilepsy: Efficacy and Silvestro S, Mammana S, Cavalli E, et al. Use of cannabidiol in the treatment of epilepsy: Efficacy and
security in clinical trials. Molecules 2019;24(8);1459-1487. https://doi.org/10.3390/molecules24081459 security in clinical trials. Molecules 2019;24(8);1459-1487. https://doi.org/10.3390/molecules24081459
8. Detyniecki K, Hirsch LJ. Cannabidiol for epilepsy: Trying to see through the haze. Lancet Neurol 8. Detyniecki K, Hirsch LJ. Cannabidiol for epilepsy: Trying to see
2016;(3):235-237. https://doi.org/10.1016/S1474-4422(16)00002-8

19. Whiting PF, Wolff RF, Deshpande S, et al. Cannabinoids for medical use: A systematic review and meta-analysis. JAMA 2015;313(24):2456-2473. https://doi.org/10.1001/jama.2015.6358

20. Peres FF, Lima, AC, Hallak JEC, Crippa JA, Abilio VC. Cannabidiol as a promising strategy to treat and prevent movement disorders? Front Pharmacol 2018;9;482. https://doi.org/10.3389/fphar.2018.00482

21. Bruni N, Pepa CD, Oliaro-Bosso S, Pessione E, Gastaldi D, Dosio F. Cannabinoid delivery for pain and inflammation treatment. Molecules 2018;23(10):2478. https://doi.org/10.3390/molecules23102478

22. Abizaid A, Merali Z, Anisman H. Cannabis: A potential efficacious intervention for PTSD or simply snake oil? J Psychiatry Neurosci 2019;44(2):75-78. https://doi.org/10.1503/jpn.190021

23. Gaston TE, Szaflarski JP. Cannabis for the treatment of epilepsy. Curr Neurol Neurosci Rep 2018;18(11);73-77. https://doi.org/10.1007/s11910-018-0882-y

24. Liu Y-J, Chen J, Li X, et al. Research progress on adenosine in central nervous system diseases. CNS Neurosci Ther 2019;25(9):899-910. https://doi.org/10.1111/cns.13190
Niti

25. Welty TE, Luebke A, Gidal BE. Cannabidiol: Promise and pitfalls. Epilepsy Curr 2014;14(5):250-252. https://doi.org/10.5698/1535-7597-14.5.250

26. Cilio MR, Thiele EA, Devinsky O. The case for assessing cannabidiol in epilepsy. Epilepsia 2014;55(6):787-790. https://doi.org/10.1111/epi.12635

27. Robson P. Therapeutic aspects of cannabis and cannabinoids. Br J Psych 2001;178(2):107-115. https:// doi.org/10.1192/bjp.178.2.107

28. Duncan JS, Sander JW, Sisodiya SM, et al. Adult epilepsy. Lancet 2006;367(9516):1087-1100. https:// doi.org/10.1016/S0140-6736(06)68477-8

29. Reddy DS. Clinical pharmacology of current antiepileptic drugs. Int J Pharm Sci Nanotechnol 2014;7(1):2305-2319.

30. Devinsky O, Marsh E, Friedman D, et al. Cannabidiol in patients with treatment-resistant epilepsy: An open-label interventional trial. Lancet Neurol 2016;15(3):270-278. https://doi.org/10.1016/S14744422(15)00379-8

31. Devinsky O, Nabbout R, Miller I, et al. Long-term cannabidiol treatment in patients with Dravet syndrome: An open-label extension trial. Epilepsia. 2019;60(2):294-302. https://doi.org/10.1111/ epi. 14628

32. Laux LC, Bebin EM, Checketts D, et al. Long-term safety and efficacy of cannabidiol in children and adults with treatment resistant Lennox-Gastaut syndrome or Dravet syndrome: Expanded access program results. Epilepsy Res 2019;154:13-20. https://doi.org/10.1016/j.eplepsyres.2019.03.015

33. Thiele EA, Marsh ED, French JA, et al. Cannabidiol in patients with seizures associated with LennoxGastaut syndrome (GWPCARE4): A randomized, double-blind, placebo-controlled phase 3 trial. Lancet 2018;391(10125):1085-1096. https://doi.org/10.1016/S0140-6736(18)30136-3

34. Thiele EA, March E, Mazurkiewicz-Beldzinska M, et al. Cannabidiol in patients with Lennox-Gastaut syndrome: Interim analysis of an open-label extension study. Epilepsia 2019;60(3):410-428. https:// doi.org $/ 10.1111 /$ epi.14670

35. Chen JW, Borgelt LM, Blackmer AB. Cannabidiol: A new hope for patients with Dravet or Lennox-Gastaut syndromes. Ann Pharmacother 2019;53(6):603-611. https://doi. org/10.1177/1060028018822124

36. Da Silva Santos R, Galdino G. Endogenous systems involved in exercise-induced analgesia. J Physiol Pharmacol 2018;69(1):3-13. https://doi.org/10.26402/jpp.2018.1.01

Pharmacol 2018;69(1):3-13. https://doi.org/10.26402/jpp.2018.1.01
7. Massi P, Solinas M, Cinquina V, et al. Cannabidiol as potential anticancer drug. Br J Clin Pharmacol Massi P, Solinas M, Cinquina V, et al. Cannabidiol as potential antica
2013;75(2);303-312. https://doi.org/10.1111/j.1365-2125.2012.04298.x

38. Soltesz I, Alger BE, Kano M, et al. Weeding out bad waves: Towards selective cannabinoid circuit control in epilepsy. Nat Rev Neurosci 2015;16;264-277. https://doi.org/10.1038/nrn3937

39. Ludanyi A, Eross L, Czirják S, et al. Downregulation of the $\mathrm{CB}_{1}$ cannabinoid receptor and related molecular elements of the endocannabinoid system in epileptic human hippocampus. J Neurosci 2008;28(12):2976-2990. https://doi.org/10.1523/JNEUROSCI.4465-07.2008

40. Cappasso R, Borrelli F, Aviello G, et al. Cannabidiol extracted from Cannabis sativa selectively inhibits inflammatory hypermotility in mice. Br J Pharmacol 2008;154(5):1001-1008. https://doi.org/10.1038/ bjp. 2008.177

41. O'Connoll BK, Glos D, Devinsky O. Cannabinoids in treatment-resistant epilepsy: A review. Epilepsy Behav 2017;70:341-348. https://doi.org/10.1016/i.yebeh.2016.11.012

42. Liou GI, Auchampach JA, Hillard CJ, et al. Mediation of cannabidiol anti-inflammation in the retina by equilibrative nucleoside transporter and $\mathrm{A}_{2 \mathrm{~A}}$ adenosine receptor. Invest Opthalmol Vis Sci 2008:49(12);5526-5531. https://doi.org/10.1167/iovs.08-2196

43. Pandolfo P, Silveirinha V, dos Santos-Rodriques A, et al. Cannabinoids inhibit the synaptic uptake of Pandolfo P, Silveirinha V, dos Santos-Rodriques A, et al. Cannabinoids inhibit the synaptic uptake of
adenosine and dopamine in the rat and mouse striatum. Eur J Pharmacol 2011;655(1-3):38-45. https:// doi.org/10.1016/j.ejphar.2011.01.013

44. Franco V, Perucca E. Pharmacological and therapeutic properties of cannabidiol for epilepsy. Drugs 2019;79(13):1435-1454. https://doi.org/10.1007/s40265-019-01171-4

Accepted 14 November 2019. 